\title{
Pemecahan Moda Terpandu dan Pengamatan Koefisien Pemantulan pada Pandu Gelombang Planar tanpa dan dengan Kisi
}

\author{
SPARISOMA VIRIDI \\ Laporan kunjungan ke MESA+ Research Institute, University of Twente, P.O. box 217, 7500 AE Enschede, The Netherlands \\ Email: dancewithghost@yahoo.com \\ November $21^{\text {st }}, 2001$
}

Abstrak. Pemecahan Mode Terpandu dapat dilakukan dengan menerapkan syarat kontinuitas pada medan listrik dan turunannya. Atau dapat pula syarat ini telah ditampung dalam transfer matriks sehingga, tidak lagi perlu diturunkan hubungan antara amplitudo pada masing-masing lapis. Dengan kedua cara ini dapat dicari $N_{\text {eff }}$ yang memenuhi solusi yang merupakan moda terpandu. Kemudian dengan metoda yang kedua ini dapat pula diletakkan kisi pada salah satu lapisan. Dengan demikian dapat diamati bagaimana profil dan juga koefisien pemantulan pada struktur tersebut.

Kata kunci: moda terpandu, matriks transfer, kisi, pandu gelombang, koefisien pemantulan, bisection, akar persamaan

\section{Pendahuluan}

Dua buah cara untuk mendapatkan moda terpandu telah digunakan digunakan dalam perhitungan ini. Pertama dengan langsung menerapkan syarat kontinuitas untuk medan listrik pada setiap batas antarmuka lapisan. Dan yang kedua adalah dengan menggunakan matriks transfer. ${ }^{[1]}$ Cara pertama diterapkan untuk pandu gelombang dengan tiga lapis dan cara kedua diterapkan untuk pandu gelombang dengan empat lapis tanpa dan dengan kisi. Untuk dengan adanya kisi hal ini telah dilakukan dan dapat diamati bagaimana kelakuan koefisien pemantulan untuk berbagai nilai $N_{\text {eff, dengan mengunakan Couple Mode }}$ Theory (CMT). ${ }^{[2]}$ Pada tulisan ini telah dicoba untuk kembali mendapatkan hasil tersebut.

\section{Teori}

Masalah yang akan dipecahkan adalah moda terpandu untuk gelombang dengan polarisasi TE. Dengan lebih dahulu meninggalkan faktor

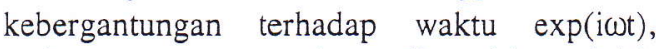
maka persamaan yang harus dipecahkan adalah

$$
\left\{\partial_{x x}+\partial_{z z}+k_{0}^{2} n^{2}(x, z)\right\} E_{y}(x, z)=0
$$

Di sini $k_{0}$ adalah bilangan gelombang dalam vakum, dan $n$ adalah indeks bias yang memiliki kebergantungan terhadap $\mathrm{z}$ apabila kisi diikutsertakan dalam perhitungan.

\subsection{Kasus Tiga Lapis dan KontinutTas}

Profil pandu gelombang yang akan dihitung memiliki bentuk seperti digambarkan pada Gambar 1 berikut ini:

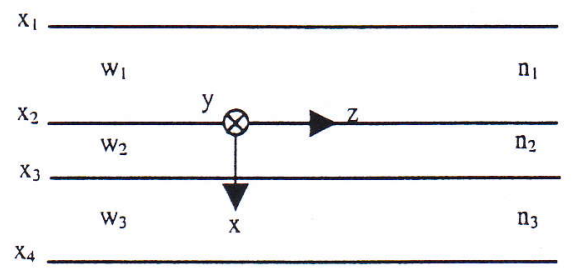

Gambar 1. Strutur geometri kasus tiga lapis.

Nilai indeks bias $n_{l}, n_{2}$ dan $n_{3}$ yang digunakan memiliki syarat

$$
n_{2}>n_{1}, \quad n_{2}>n_{3}
$$

agar dapat terjadi moda terpandu pada lapis kedua. Kemudian dengan menggunakan suatu nilai $N_{\text {eff }}$ yang akan dicari, dapat dihitung bilangan gelombang untuk tiap-tiap lapis, yaitu:

$$
\begin{aligned}
& k_{1}=k_{0} \sqrt{N_{e f f}^{2}-n_{1}^{2}} \\
& k_{2}=k_{0} \sqrt{n_{2}^{2}-N_{e f f}^{2}} \\
& k_{3}=k_{0} \sqrt{N_{e f f}^{2}-n_{3}^{2}}
\end{aligned}
$$

Dalam kasus ini $n$ hanya merupakan fungsi dari $x$.

$$
n=n(x)
$$

Sehingga dalam tiap-tiap lapis dapat dipilih solusi dengan bentuk yang hanya bergantung terhadap $x$, kebergantungan terhadap $z$ telah ditampung oleh faktor $\exp (-i \beta z)$.

$$
\begin{aligned}
& E_{1}=A_{1,+} \exp \left(k_{1} x\right) \\
& E_{2}=A_{2,+} \exp \left(i k_{2} x\right)+A_{2,-} \exp \left(-i k_{2} x\right)
\end{aligned}
$$




$$
E_{3}=A_{3,+} \exp \left(k_{3} x\right)+A_{3,-} \exp \left(-k_{3} x\right)
$$

Tanda subscript positif menunjukkan cahaya yang merambat ke arah $-x$ dan tanda negatif menunjukkan cahaya merambat pada arah sebaliknya. Kemudian dengan menerapkan syarat kontinuitas

$$
\begin{aligned}
& \left.E_{1}\right|_{x=0}=\left.E_{2}\right|_{x=0} \\
& \left.\partial_{x} E_{1}\right|_{x=0}=\left.\partial_{x} E_{2}\right|_{x=0} \\
& \left.E_{2}\right|_{x=w}=\left.E_{3}\right|_{x=w} \\
& \left.\partial_{x} E_{2}\right|_{x=w}=\left.\partial_{x} E_{3}\right|_{x=w}
\end{aligned}
$$

Akan dapat diperoleh hubungan berikut ini:

$$
\begin{aligned}
& A_{2,+}=\frac{1}{2}\left(1-i \frac{k_{1}}{k_{2}}\right) A_{1,+} \\
& A_{2,+}=\frac{1}{2}\left(1-i \frac{k_{1}}{k_{2}}\right) A_{1,+} \\
& A_{3,+}=\frac{1}{2 k_{3}}\left\{\left(k_{3}+i k_{2}\right) e^{i k_{2} w} A_{2,+}+\left(k_{3}-i k_{2}\right) e^{-i k_{2} w} A_{2,-}\right\} \\
& A_{3,-}=\frac{1}{2 k_{3}}\left\{\left(k_{3}-i k_{2}\right) e^{i k_{2} w} A_{2,+}+\left(k_{3}+i k_{2}\right) e^{-i k_{2} w} A_{2,-}\right\}
\end{aligned}
$$

Sehingga secara tidak langsung dapat dibangun suatu fungsi, katakan saja $f$, yang menghubungkan antara $N_{\text {eff }}$ dan $A_{3_{1}+}$.

$$
A_{3,+}=f\left(N_{e f f}\right)
$$

Kemudian moda yang dimaksud adalah suatu nilai $N_{\text {eff }}$ yang membuat $A_{3,+}$ menjadi nol atau mendekati nol. Atau dengan kata lain permasalah ini menjadi permasalah pencarian akar persamaan $f$ dengan variabel $N_{\text {eff }}$.

Metoda yang akan digunakan di sini adalah metoda Bisection. Metoda ini merupakan metoda yang paling sederhana untuk mencari akar-akar suatu persamaan. Metoda lain sebagai alternatif misalnya Runge-Kutta dan Newton-Raphson.

Secara sederhana algoritma Bisection dapat dituliskan sebagai berikut:

1. Tentukan batas pencarian akar, Neffmin dan Nef fmax.

2. Nyatakan sebagai variabel Neff 1 dan Neff2 berturut-turut.

3. Hitung $f 1$ dan $f 2$ dengan masukan Neff 1 dan Neff2. Di mana $f 1=f(\operatorname{Neff1}), f 2$ $=f(\operatorname{Neff} 2)$.
4. Hitung hasil perkalian f1 dan f2 nyatakan dalam $\mathrm{f} 12$.

5. Jika $£ 12<0$ maka lanjutkan langkah 6 , jika tidak lanjutkan langkah 13.

6. Tentukan Neff3 dengan membagi dua rentang Neff1 dan Neff 2 , yaitu Neff $3=$ $($ Neff1 + Neff2)/2.

7. Hitung $f 3$, di mana $£ 3=f(\operatorname{Nef} f 3)$.

8. Jika $|£ 3|<\mathrm{fmin}$, batas yang dianggap mencerminkan bahwa Neff3 merupakan akar persamaan f, lanjutkan langkah 16 . Misalnya $\mathrm{fmin}=1 \mathrm{E}-10$.

9. Hitung $f 13$ dan $£ 23$, di mana $f 13=$ $f 1 * f 3$ dan $f 23=f 2 * f 3$.

10. Pilih hasil perkalian yang bernilai lebih kecil dari 0, jika ada lanjutkan langkah 11 jika tidak ada lanjutkan langkah 13.

11. Jika $f 13<0$ maka Neff1 = Nef£1 dan Neff2 $=$ Neff 3 , jika $f 23<0$ maka Neff1 $=\operatorname{Neff2}$ dan Neff2 $=\operatorname{Neff} 3$.

12. Kembali ke langkah 3 .

13. Hitung aneff $=($ Neff2 - Neff1) $/$ NN. Misalnya NN $=1000$.

14. Neff $1=$ Neff $1+$ dNeff.

15. Kembali ke langkah 3.

16. Selesai.

Apabila akar-akar persamaan ditemukan lebih dari satu maka algoritma tersebut dapat tetap digunakan dengan membagi fungsi $f$ dengan akar-akar yang telah ditemukan, dengan demikian seluruh akan akan dapat dicari.

$$
f^{(n+1)}\left(N_{e j f}\right)=f^{(n)}\left(N_{e j}\right) / \prod_{i=1}^{n}\left(N_{e j]}-N_{\text {NefJ }}^{i}\right)
$$

Di mana indeks $(n)$ menyatakan jumlah akar yang telah ditemukan, dalam hal ini $f^{(0)}$ adalah $f$ dalam persamaan (18).

\subsection{Kasus Empat Lapis dan Matriks Transfer}

Transfer matriks adalah metoda yang mentransfer matriks yang menghubungkan antara medan dengan turunannya, yaitu matriks $u$.

$$
\begin{aligned}
& E_{y}(x) \equiv p(x)=b_{+}(x)+b_{-}(x) \\
& \partial_{x} E_{y}(x) \equiv q(x)=b_{+}(x)-b_{-}(x)
\end{aligned}
$$

dengan matriks $u$ adalah

$$
q=u p
$$

dan

$$
b_{ \pm}(x)=\exp ( \pm D x) b_{ \pm}(0)
$$


dengan $D$ adalah sebuah matriks. Hubungan antara matriks $u$ di bawah (indeks B) suatu lapis dengan $u$ pada atas lapis (indeks $\mathrm{T}$ ) berikutnya adalah sebagai berikut:

$u_{p}^{T}=D_{p}^{-1} M_{p}^{-1} M_{p-1} D_{p-1} u_{p-1}^{B} M_{p-1}^{-1} M_{p}$

Hubungan antara $u$ dalam tiap lapis adalah

$u_{p}^{B}=C_{p, l} S_{p, l}^{-1}-S_{p, l}^{-1}\left(u_{p}^{T}+C_{p, l} S_{p, l}^{-1}\right)^{-1} S_{p, l}^{-1}$

with

$$
\begin{aligned}
& C_{p, t}=\frac{1}{2}\left(D_{p, t}^{+}+D_{p, t}^{-}\right) \\
& S_{p, t}=\frac{1}{2}\left(D_{p, t}^{+}-D_{p, t}^{-}\right) \\
& D_{p, l}^{ \pm}=\exp \left( \pm D_{p} t_{p}\right)
\end{aligned}
$$

Untuk struktur ini, $M$ adalah matriks identitas. Dan $D$ adalah matriks diagonal dengan $-\alpha^{2}$ sebagai elemen matriksnya.

$$
\alpha_{p}=\sqrt{\beta^{2}-k_{0}^{2} n_{p}^{2}}
$$

untuk masing-masing lapis.

Kemudian hubungan antara matriks kolom $p$ dalam lapis dan antar lapis adalah sebagai berikut:

$$
\begin{aligned}
& p_{\rho}^{B}=M_{p}^{-1} M_{p+1} p_{p+1}^{T} \\
& p_{p}^{T}=Q_{s, l} P_{p}^{B} \\
& Q_{p, l}=S_{p, l}\left(S_{p, l}^{-1} C_{p, l}-u_{p}^{B}\right)
\end{aligned}
$$

dan beberapa hubungan yang mungkin diperlukan

$$
\begin{aligned}
& R_{q 1}=\left(-u_{q}^{T}+I\right)\left(u_{q}^{T}+I\right)^{-1} \\
& b_{q}^{T-}=R_{q 1} b_{q}^{T+} \\
& b_{p}^{T / B \pm}=\frac{1}{2}\left(I \pm u_{p}^{T / B}\right) p_{p}^{T / B}
\end{aligned}
$$

Kemudian strategi yang digunakan untuk mencari solusi adalah: ${ }^{[2]}$

1. Pada salah satu ujung layer, misalnya saja layer 1 , ditetapkan bahwa hanya ada bagian yang meluruh, sehingga $u_{1}^{B}=I$.

2. Berturut-turut dilakukan transfer matriks $u$ menggunakan persamaan (24) dan (25) sehingga tercapati matriks $\mathrm{u}_{\mathrm{q}}^{\mathrm{T}}$. Dengan $q$ adalah layer terbawah dalam struktur.

3. Kemudian dengan menggunakan persamaan (30)-(32) dapat diperoleh medan dalam setiap lapis.
4. Perhitungan dihentikan sampai diperoleh nilai $b_{q}{ }^{T+}$ yang cukup kecil, misalnya saja $10^{-10}$.

\subsection{MATRIKS TRANSFER DAN $|\mathrm{r}|$}

Dalam kasus berikut ini masih dibahas struktur yang sama hanya diperkenalkan kisi pada lapis ketiga dan lapis kedua diberikan indeks bias yang sama dengan lapis pertama. Untuk kasus lapis di mana terdapat kisi diperkenalkan cara untuk menyatakan perbedaan indeks biar akibat adanya kisi dengan menggunakan ekspansi deret Fourier.

$$
\begin{aligned}
& k_{0}^{2} n_{\text {grating }}^{2}(z)=k_{0}^{2} n_{s, a}^{2}+\sum_{m \neq 0} \xi_{s, m} \exp (i m K z) \\
& \xi_{s, m}=\frac{1}{d} \int_{0}^{d} k_{0}^{2} n_{\text {grating }}^{2} \exp (-i m K z) d z
\end{aligned}
$$

Dengan $d$ adalah perioda kisi dan $K$ adalah

$$
K=\frac{2 \pi}{d}
$$

adalah bilangan gelombang kisi. Kemudian dapat didefinisikan frekuensi spasial sepanjang $z$ yang berkaitan dengan suatu frekuensi spasial dalam daerah Brillioun pertama, $\beta$ :

$$
\begin{aligned}
\beta-r K, \beta-(r-1) K, \ldots \\
\beta, \ldots, \\
\ldots, \beta+r K \equiv \beta_{1}, \ldots, \beta_{2 r+1}
\end{aligned}
$$

di mana $r$ adalah ukuran orde ketelitian. Untuk kasus kisi ini dapat didefinisikan $\alpha$ seperti pada persamaan (29), yaitu

$$
\alpha_{s, L}=\sqrt{\beta_{L}^{2}-k_{0}^{2} n_{s, L}}
$$

dengan $\operatorname{Re}\left(\alpha_{s, L}\right)>0$ dan $\operatorname{Im}\left(\alpha_{s, L}\right)>0$ jika $\operatorname{Re}\left(\alpha_{s, L}\right)>0$, dengan $s$ adalah nomor lapis, $s=$ I.. $q$ dan $L=1$.. $2 r+1$. Medan dalam lapis $s$ dapat dituliskan dalam bentuk

$$
E_{s}(x, z)=\sum_{L} e_{s, L}(x) \exp \left(-i \beta_{L} z\right)
$$

atau dalam bentuk

$$
E_{s}(x, z)=\sum_{L} c \exp \left(\alpha x-i \alpha_{L} z\right)
$$

Kemudian dengan menggunakan ekspansi indeks bias kisi dalam deret Fourier di atas, maka dapat diperoleh peroleh persamaan nilai eigen untuk $c$ dengen mengumpulkan suku- 
suku yang memiliki frekuensi spasial yang sama sepanjang $z$.

$$
N_{c}=-a^{2} c
$$

dengan $N$ adalah

$$
N=\left[\begin{array}{cccc}
-\alpha_{1}^{2} & \xi_{1} & \ldots & \xi_{2 r} \\
\xi_{-1} & -\alpha_{2}^{2} & \ldots & \xi_{2 r-1} \\
\ldots & \ldots & \ldots & \ldots \\
\xi_{-2 r} & \xi_{-(2 r-1)} & \ldots & -\alpha_{2 r+1}^{2}
\end{array}\right]
$$

Dengan menyimpan vektor eigen dalam matriks $M$ dan nilai a dalam matriks diagonal $D_{s, a}$. Untuk kasus tanpa kisi maka, $M$ dan $N$ adalah matriks identitas.

Kemudian $|\mathrm{r}|$ dapat diperoleh melalui rumus

$$
r_{41}=\left(u_{4}^{T}-I\right)\left(u_{4}^{T}+1\right)^{-1}
$$

untuk kasus 4 lapis. Sedangkan untuk kasus q lapis dapat dihitung menggunakan rumusan yang sama.

$$
r_{q 1}=\left(u_{q}^{T}-I\right)\left(u_{q}^{T}+1\right)^{-1}
$$

Masing-masing posisi dalam diagonal matrix menunjukkan nilai $r$ yang bersesuain dengan komponen-komponen moda Floquet.

\section{Hasil Perhitungan Numerik}

Hasil perhitungan numerik untuk masingmasing kasus adalah sebagai berikut. Untuk kedua kasus pertama hasil akan dibandingkan dengan perhitungan yang diperoleh menggunakan piranti lunak ATR Guide sedangkan kasus ketiga akan dibandingkan dengan ATR Guide untuk kasus tanpa kisi dan dengan yang telah dihitung oleh $\mathrm{H}$. Hoekstra ${ }^{[1]}$ untuk kasus dengan kisi dalam rangka mendapatkan koefisien pemantulan, $r$.

\subsection{Kasus Tiga Lapis dan KontinutTas}

Hasil perhitungan diperoleh dengan menggunakan kode dalam $\mathrm{C}++$.

\section{parameter-1 dan hasil:}

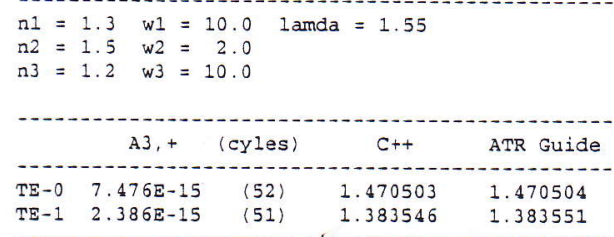

parameter -2 dan hasil:

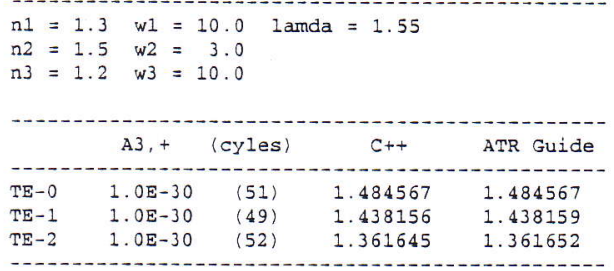

parameter-3 dan hasil:

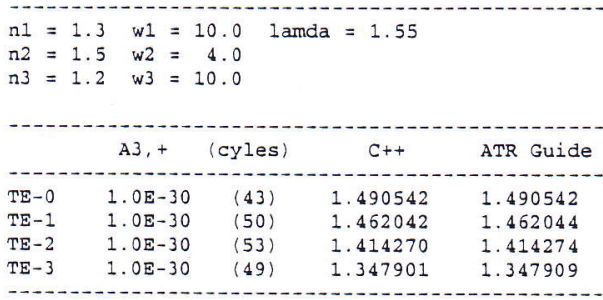

parameter-4 dan hasil:

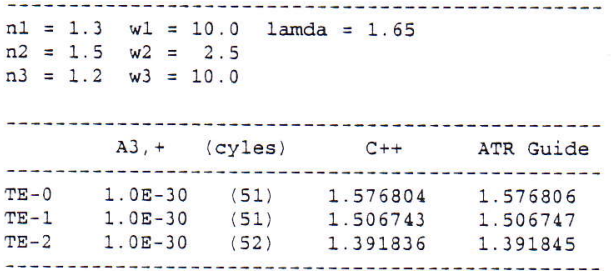

Sesaat terlihat bahwa untuk semakin tinggi mode semakin besar perbedaan hasil yang diperoleh apabila dibandingkan dengan hasil ATR Guide. Hal ini dapat dilihat pada grafik berikut ini.

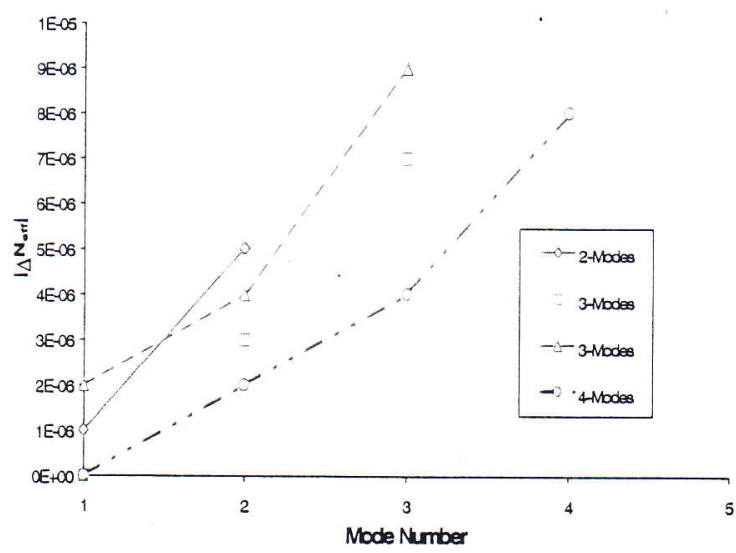

Gambar 1. Grafik $\mid \Delta N_{\text {eff }}$ terhadap nomor moda.

\subsection{Kasus Empat Lapis Dan Matriks Transfer}

Dengan menggunakan transfer matriks untuk mencari moda terpandu diperoleh beberapa hasil berikut ini. Panjang gelombang yang digunakan adalah $1.550 \mu \mathrm{m}$. 
parameter-1 dan hasil:

\begin{tabular}{|c|c|c|}
\hline Layer & width & $\mathrm{n}$ \\
\hline 1 & 10.000 & 1.0000 \\
\hline 2 & 1.000 & 1.5000 \\
\hline 3 & 0.500 & 1.8065 \\
\hline 4 & 1.000 & 1.5000 \\
\hline 5 & 10.000 & 1.0000 \\
\hline
\end{tabular}

\begin{tabular}{|c|c|c|}
\hline & ATR Guide & MATLAB \\
\hline $\mathrm{TE}-0$ & 1.548649 & 1.648649 \\
\hline $\mathrm{TE}-1$ & 1.420486 & 1.420486 \\
\hline $\mathrm{TE}-2$ & 1.343947 & 1.343947 \\
\hline $\mathrm{TE}-3$ & 1.150211 & 1.150211 \\
\hline
\end{tabular}

parameter-2 dan hasil:

\begin{tabular}{|c|c|c|}
\hline Layer & width & n \\
\hline 1 & 10.000 & 1.0000 \\
\hline 2 & 1.000 & 1.5000 \\
\hline 3 & 1.000 & 1.8065 \\
\hline 4 & 1.000 & 1.5000 \\
\hline 5 & 10.000 & 1.0000 \\
\hline
\end{tabular}

\begin{tabular}{|c|c|c|}
\hline & ATR Guide & MATLAB \\
\hline $\mathrm{TE}-\mathrm{O}$ & 1.732454 & 1.732454 \\
\hline $\mathrm{TE}-1$ & 1.535641 & 1.535641 \\
\hline $\mathrm{TE}-2$ & 1.397110 & 1.397110 \\
\hline $\mathrm{TE}-3$ & 1.322780 & 1.322780 \\
\hline $\mathrm{TE}-4$ & 1.126820 & 1.126820 \\
\hline
\end{tabular}

parameter-3 dan hasil:

\begin{tabular}{|c|c|c|}
\hline Layer & width & $n$ \\
\hline 1 & 10.000 & 1.0000 \\
\hline 2 & 1.000 & 1.5000 \\
\hline 3 & 0.250 & 1.8065 \\
\hline 4 & 1.000 & 1.6000 \\
\hline 5 & 10.000 & 1.0000 \\
\hline
\end{tabular}

\begin{tabular}{|c|c|c|}
\hline & ATR Guide & MATLAB \\
\hline TE-O & 1.601656 & 1.601656 \\
\hline TE-1 & 1.446720 & 1.446720 \\
\hline TE-2 & 1.329621 & 1.329621 \\
\hline TE-3 & 1.089296 & 1.089296 \\
\hline
\end{tabular}

parameter -4 dan hasil:

\begin{tabular}{|c|c|c|}
\hline Layer & width & $\mathrm{n}$ \\
\hline 1 & 10.000 & 1.0000 \\
\hline 2 & 1.000 & 1.5000 \\
\hline 3 & 0.250 & 1.8065 \\
\hline 4 & 0.500 & 1.6000 \\
\hline 5 & 10.000 & 1.2000 \\
\hline
\end{tabular}

\begin{tabular}{|c|c|c|}
\hline & ATR Guide & MATLAB \\
\hline TE-O & 1.587053 & 1.587053 \\
\hline$T E-1$ & 1.379393 & 1.379393 \\
\hline$T E-2$ & 1.219633 & 1.219633 \\
\hline
\end{tabular}

Terlihat bahwa perhitungan menggunakan MatLab memberikan hasil yang sama dengan perhitungan menggunakan ATR Guide.

\subsection{MATRIKS TRANSFER DAN $|\mathrm{r}|$}

Sebelum menghitung kasus 4 lapis tanpa kisi, $|r| 2$ tiap-tiap lapis telah dihitung terlebih dahulu untuk dibandingkan dengan hasil ATR Guide. Hal ini dilakukan untuk memeriksa terjadinya kesalahan dalam metoda transfer matriks.

Data untuk tiap titik pada setiap pengamatan telah dicocokkan. Grafik yang diperoleh digambarkan saling bertindihan untuk menunjukkan hasil yang memiliki nilai yang sama. Grafik dengan garis utuh adalah hasil ATR Guide sedangkan grafik dengan bulatan adalah hasil MatlLab.

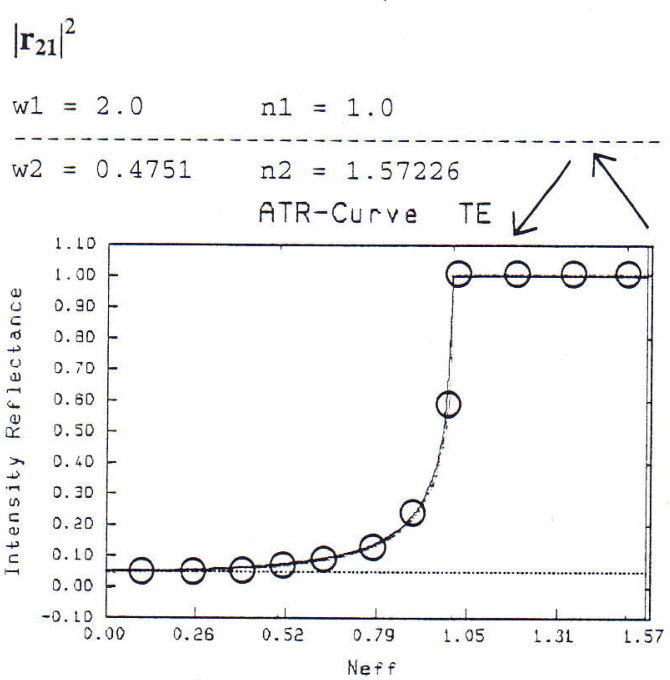

Gambar 2. Grafik $\left|r_{21}\right|^{2}$ terhadap $N_{\text {eff }}$

$\left|\mathbf{r}_{31}\right|^{2}$

$\mathrm{w} 1=2.0 \quad \mathrm{n} 1=1.0$

-

$\mathrm{w} 2=0.4751 \quad \mathrm{n} 2=1.57226$

$\mathrm{w} 3=0.5 \quad \mathrm{n} 3=1.98595$

ATR-Curve TE

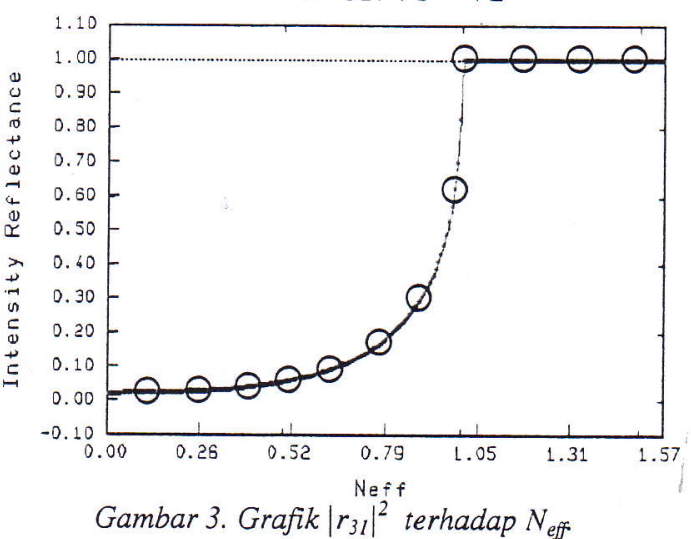



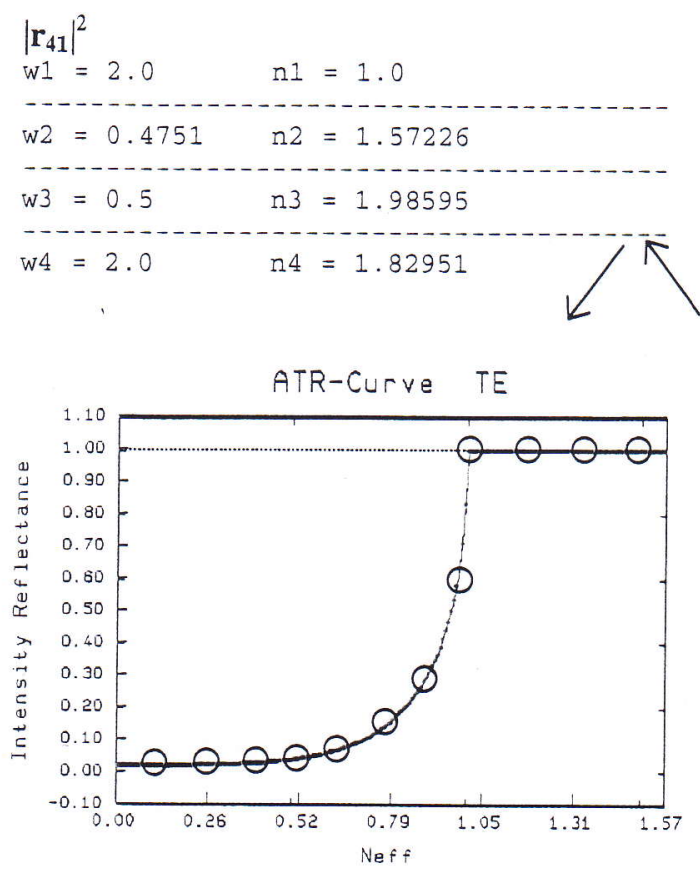

Gambar 4. Grafik $\left|r_{41}\right|^{2}$ terhadap $N_{\text {eff }}$

Untuk kasus tanpa kisi hasil yang diperoleh melalui MatLab memiliki nilai yang sama dengan hasil yang diperoleh melalui ATR Guide.

Sedangkan untuk hasil dengan kisi untuk telah diperoleh hasil yang mirip dengan referensi acuan. ${ }^{[2]}$ Akan tetapi perbedaan atau kesalahan perhitungan belum dapat diperkirakan. Hasil tersebut dapat dilihat pada Gambar 5. berikut ini.

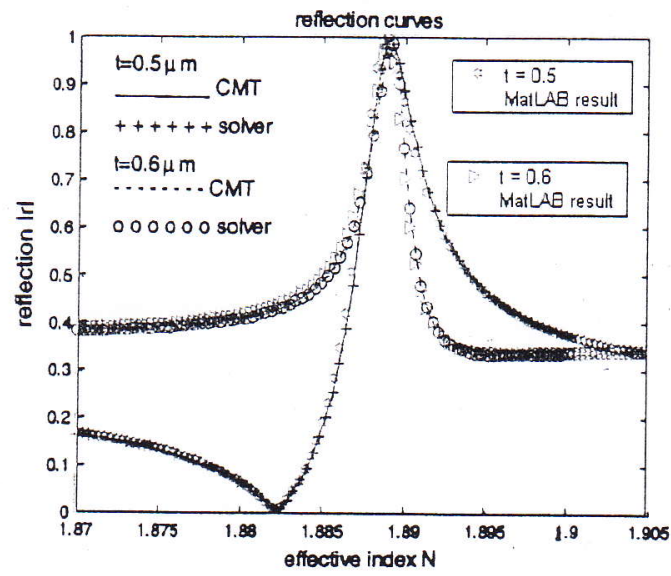

Gambar 5. Grafik $\left|r_{41}\right|$ terhadap $N_{\text {eff }}$

Besarang $N_{\text {eff }}$ yang dimaksud di sini adalah

$N_{\text {eff }}^{1}=N_{\text {eff }}-K / k_{0}$

\section{Ikhtisar}

Untuk sementara diperoleh bahwa penyelesaian moda terpandu dengan menggunakan matriks tranfer memiliki nilai yang lebih baik dibandingkan dengan hanya menggunakan syarat kontinuitas bagi medan maupun turunannya pada batas-batas lapisan, apabila dibandingkan dengan hasil yang diperoleh menggunakan ATR Guide. Sedangkan untuk perhitungan $|r|$ atau $|r|^{2}$ menggunakan matriks transfer untuk kasus tanpa kisi memperoleh hasil yang sama dengan hasil dari ATR Guide. Untuk kasus dengan kiri telah diperoleh hasil yang sama dengan referensi. ${ }^{[2]}$

\section{Konsultasi}

H. Hoekstra, H. Alatas, H. P. Handoyo, Yohan, Casimir, Sabol, dan H.P Uranus.

\section{Referensi}

1. J. Cityroky Â., S.Helfert, R. Pregla, Optical and Quantum Electronics, 30 (1998) 343-358.

2. Hugo, J. W. M. Hoekstra, Optical and Quantum Electronics, 32 (2000) 735-758.

3. H. Hoekstra, Summary of lecture presented on 12-2-2001 in WS-MAMOA, Bandung (2001).

4. Theodor Tamir, R. C. Alferness, Guidedwave Optoelectronics, Springer-Verlag, Berlin, (1990) 12-27.

5. H. Hoekstra, Summary of lecture presented on 29-1-2001 in WS-MAMOA, Bandung (2001).

6. Jurgen R. Meyer0Arendt, Introduction to Classical and Modern Optics, Prentice Hall, Englewood Cliffs, New Jersey, $4^{\text {th }}$ Edition (1995) 8.

7. Reinhard März, Integrated Optics Design and Modeling, Artech House, Boston, (1995) 39.

8. Charles W. Steele, Numerical Computation of Electric and Magnetic Fields, Chapman \& Hall, (1997) 29.

9. D. Stauffer, F. W. Helh, V. Winkelmann, J.G. Zabolitzky, Computer Simulation and Computer Algebra: Lecturer for Beginner, Springer-Verlag, Berling, Second Edition (1989).

10. G. Lindfield, J. Penny, Numerical Method Using MATLAB, Ellish Horwood, New York (1995).

11. Nai-Hsiang Sun, J. of Lightwave Tech., 15 (1997) 2301-2315. 